\title{
Análisis de ADN libre fetal para la evaluación no invasiva de trisomía (1)
}

\author{
Norton ME, Jacobsson B, Swamy GK, Laurent LC, Ranzini AC, Brar H, Tomlinson MW, \\ Pereira L, Spitz JL, Hollemon D, Cuckle H, Musci TJ, Wapner RJ. Cell-free DNA analysis \\ for non invasive examination of trisomy. N Engl J Med 2015;372(17):1589-97.
}

Análisis Crítico: Carolina Martinovic Titiro, Jorge A. Carvajal, PhD.

Unidad de Medicina Materno-Fetal, División de Obstetricia y Ginecología, Escuela de Medicina, Pontificia Universidad Católica de Chile

\section{RESUMEN (1)}

Introducción: La prueba de ADN fetal libre para trisomía fetal es altamente efectiva entre las mujeres de alto riesgo. Sin embargo ha habido pocos estudios con adecuado poder dirigidos a comparar la prueba de ADN libre con tamizaje estándar rutinario durante el primer trimestre en población prenatal. Métodos: En este estudio prospectivo multicéntrico ciego de 35 centros internacionales, asignamos mujeres embarazadas para tamizaje de aneuploidía entre las 10 y 14 semanas de gestación a tamizaje estándar (medición de translucencia nucal y análisis bioquímico) y prueba de ADN libre fetal. Las participantes recibieron el resultado del tamizaje estándar; el resultado del ADN fetal libre fue ciego. La determinación de los resultados al nacer fue basada en test diagnósticos genéticos o examen del recién nacido. El resultado primario fue el área bajo la curva para trisomía 21 (síndrome de Down) con prueba de ADN libre fetal versus tamizaje estándar. También evaluamos la prueba de ADN libre fetal y el tamizaje estándar para evaluar el riesgo de trisomía 18 y 13. Resultados: De 18.955 mujeres que fueron enroladas, 15.841 resultados estuvieron disponibles para el análisis. El promedio de edad materna fue 30,7 años, y el promedio de edad gestacional al test fue de 12,5 semanas. El área bajo la curva para trisomía 21 fue 0,999 para la prueba de ADN libre fetal y 0,958 para tamizaje estándar $(p=0,001)$. La trisomía 21 fue detectada en 38 de 38 mujeres (100\%; IC95\% 90,7-100) en el grupo de prueba de ADN libre fetal, comparado con
30 de 38 mujeres (78,9\%; IC95\% 62,7-90,4) en el grupo de tamizaje estándar $(p=0,008)$. La tasa de falsos positivos fue $0,06 \%$, IC $95 \% 0,03-0,11$ ) en el grupo de prueba de ADN libre fetal y 5,4\%; IC95\% $5,1-5,8$ en el grupo de tamizaje estándar $(p<0,001)$. El valor predictivo positivo para prueba de ADN libre fetal fue 80,9\%; IC95\% 66,7-90,9 comparado con 3,4\%; IC95\% 2,3-4,8) para tamizaje estándar $(p<0,001)$. Conclusiones: En esta gran población de tamizaje prenatal de rutina, la prueba de ADN fetal libre para trisomía 21 tiene mayor sensibilidad, menor tasa de falsos positivos y mayor valor predictivo positivo, que el tamizaje estándar con la medición de translucencia nucal y análisis bioquímico (Fundado por Airosa Diagnostics and Perinatal Quality Foundation; NEXT Clinical Trials.gov number, NCT01511458).

\section{ANÁLISIS DE LA INVESTIGACIÓN}

\section{A. Relevancia clínica de la investigación}

El uso de ADN fetal libre como tamizaje de aneuploidía se realiza desde el año 2011 con altas tasas de detección de trisomía 21 ; cerca de $99 \%$ con $0,1 \%$ de falsos positivos (2-3). El uso del ADN libre fetal mejora sustancialmente la tasa de detección de aneuploidía comparado con el tamizaje estándar que incluye edad materna, marcadores ultrasonográficos (translucencia nucal, hueso nasal, ductus venoso y regurgitación tricuspidea) y análisis bioquímico que logra una detección del $97 \%$ con $3 \%$ de falsos positivos (4). Es por esto que en la práctica 
clínica la prueba de ADN libre fetal podría reducir el número de procedimientos invasivos al presentar una importante reducción de la tasa de falsos positivos. Sin embargo, la mayoría de los estudios se han realizado en población de alto riesgo de aneuploidía, habitualmente en mujeres con translucencia nucal aumentada o tamizaje bioquímico sugerente. Se deduce la relevancia clínica de este estudio para determinar las tasas de detección de la prueba de ADN libre fetal en población general, permitiendo plantear la prueba de ADN fetal como tamizaje rutinario de aneuploidía en población general.

\section{B. EL ESTUDIO (1)}

Diseño: Estudio de cohorte prospectivo, multicéntrico, ciego. Se enrolaron pacientes embarazadas para efectuar tamizaje de aneuploidía en el primer trimestre desde marzo de 2012 a abril de 2013 en 35 centros en seis países. A las pacientes se les extrajo una muestra para test de ADN libre fetal (test de DNA libre fetal prenatal Ariosa Laboratory) y se les realizó el tamizaje habitual de aneuploidía del primer trimestre con medición de translucencia nucal y análisis bioquímico. Se evaluaron las tasas de abortos espontáneos, abortos provocados y parto, además se evaluaron los resultados del test de ADN libre fetal prenatal, resultados de estudios genéticos invasivos prenatales, el examen físico y el resultados del estudio genético post natal en los casos de examen físico sugerente de aneuploidía. Resultado principal: El resultado primario es el área bajo la curva de la curva Roc para tamizaje de trisomía 21 con prueba de ADN libre fetal versus tamizaje estándar. Además se realizó un sub análisis en pacientes de bajo riesgo de aneuploidía (menores de 35 años o menos de 1/270 en tamizaje estándar). Resultado secundario: Evaluación de prueba de ADN libre fetal versus tamizaje estándar para estimar riesgo de trisomía 18 y trisomía 13. Participantes: Mujeres mayores de 18 años que cursaban embarazos únicos entre 10 y 14,3 semanas de gestación, se excluyó a pacientes con aneuploidía materna, cáncer, que tuvieran embarazo gemelar o que se realizaron fertilización con ovodonación. Análisis primario: Entre las 15.841 pacientes incluidas en el análisis primario se encontraron 68 anomalías cromosómicas (1 en 236 embarazos). La trisomía 21 fue identificada en 38 de las 15.841 pacientes con una prevalencia de 1 en 417 embarazos. El área bajo la curva para trisomía 21 fue 0,999 para prueba de ADN libre fetal y 0,958 para tamizaje estándar $(p=0,001)$. La trisomía 21 fue detectada en 38 de 38 mujeres (100\%; IC95\% 90,7-100) en el grupo de prueba de ADN libre fetal, comparado con 30 de 38 mujeres (78,9\%; IC95\% 62,7-90,4) en el grupo de tamizaje estándar $(p=0,008)$. Hubo 9 falsos positivos de las 15.841 pacientes en el grupo de prueba de ADN libre fetal con una tasa de 0,06\%; IC95\% 0,03-0,11 y 854 falsos positivos en el grupo de tamizaje estándar con una tasa de 5,4\%; IC95\% 5,1-5,8) (p<0,001). El valor predictivo positivo para prueba de ADN libre fetal fue $80,9 \%$; IC95\% 66,7-90,9) comparado con 3,4\% IC95\% 2,3-4,8 para tamizaje estándar ( $p<0,001)$. Análisis secundario: De las 11.994 pacientes de bajo riesgo de aneuploidía en base a edad materna menor a 35 años la prueba de ADN libre fetal identificó 19 de 19 mujeres con trisomía 21 con 6 resultados falsos positivos. El valor predictivo positivo fue de 76\%; IC95\% 54,9-90,6. De las 14.957 pacientes de bajo riesgo de aneuploidía por tamizaje estándar (menos de 1/270) la prueba de ADN fetal libre identificó 8 de 8 mujeres con trisomía 21 con 8 resultados falsos positivos. El valor predictivo positivo fue de 50\%; IC95\% 24,7-75,3. Respecto de otras trisomías: hubo 10 casos de trisomía 18; la prueba de ADN libre fetal identificó 9 con 1 resultado falso positivo con una tasa de 0,01\%; IC95\% 0-0,04) y un valor predictivo positivo de $90 \%$; IC95\% 55,5-99,7) $(p<0,001)$. El tamizaje estándar identificó 8 de 10 casos con 49 resultados falsos positivos con una tasa de 0,31\%; IC95\% 0,23-0,41 y un valor predictivo positivo de 14\%; IC95\% 6,3-25,8 (p<0,001). De las 11.185 pacientes a las que se les realizó estudio para trisomía 13 hubo 2 casos confirmados, la prueba de ADN libre fetal identificó los 2 casos con 1 resultado falso positivo. El tamizaje estándar identificó 1 caso con 28 resultados falso positivo con tasas de 0,02\%; IC95\% 0-0,06 y 0,25\% IC95\% $0,17-0,36$ respectivamente $(p<0,001)$.

\section{ANÁLISIS CRÍTICO}

Validez interna: El diseño del estudio es apropiado para poder establecer las características de la prueba de ADN libre fetal como predictor de aneuploidía. El estudio minimiza las posibilidades de sesgo, pues se trata de una comparación ciega, independiente, y efectuada a todas las pacientes, con respecto a un estándar de referencia (análisis genético y examen físico del recién nacido) (5); esto permite calcular el VPP y VPN de la prueba de modo correcto. Se comparó las características de esta prueba, con respecto al tamizaje estándar de primer trimestre (ecografía y marcadores bioquímicos); demostrándose superioridad de la nueva prueba. Ambas pruebas fueron efectuadas a toda la población analizada, de modo ciego e independiente, por lo que se evitó el sesgo. Al ser un estudio multicéntrico disminuye los sesgos de selección de población ya que hay heterogeneidad en los participantes incluidos en el estudio. La pérdida de pacientes/información es mínima. El cálculo del tamaño muestral fue apropiado y se respetó el tamaño muestral en el estudio.

Validez externa. La validez externa del estudio es probablemente apropiada, y sus resultados serían 
aplicables a nuestra población. Sin embargo, la prueba de ADN libre fetal en nuestro medio es poco disponible y de alto valor, limitando su uso rutinario.

Conclusión. Se trata de un estudio de diseño impecable, que permite establecer las características de la prueba de ADN libre fetal como predictor de aneuploidía en población general. Este estudio demostró que la prueba de ADN libre fetal para el diagnóstico de trisomía 21 tiene una alta sensibilidad, baja tasa de falsos positivos y alto valor predictivo positivo, siendo superior que el tamizaje estándar combinado del primer trimestre. La información de este estudio sugiere que la prueba de ADN libre fetal debiera ser implementada de forma rutinaria. El alto costo en nuestro medio de la prueba impide su uso rutinario como tamizaje de aneuploidía en primer trimestre del embarazo. Estimamos que esta prueba no reemplaza a la medición de la translucencia nucal, pues la translucencia nucal aumentada no solo se presenta en fetos con trisomía, sino que además los fetos con translucencia nucal aumentada y cariograma normal, tiene mayor riesgo de cardiopatías congénitas y otros síndromes malformativos (esqueléticos, faciales, etc.), como así mismo mayor riesgo de muerte fetal in útero y de alteraciones en el desarrollo psicomotor.

\section{REFERENCIAS}

1. Norton ME, Jacobsson B, Swamy GK, Laurent LC, Ranzini AC, Brar H, Tomlinson MW, Pereira L, Spitz JL, Hollemon D, Cuckle H, Musci TJ, Wapner RJ. Cell-free DNA analysis for non invasive examination of trisomy. N Engl J Med 2015;372(17):1589-97.

2. Gil MM, Quezada MS, Revello R, Akolekar R, Nicolaides $\mathrm{KH}$. Analysis of cell-free DNA in maternal blood in screening for fetal aneuploidies: updated meta-analysis. Ultrasound Obstet Gynecol 2015;45(3):249-66.

3. Nicolaides $\mathrm{KH}$, Syngelaki A, Ashoor G, Birdir C, Touzet G. Noninvasive prenatal testing for fetal trisomies in a routinely screened first-trimester population. Am J Obstet Gynecol 2012;207(5):374.e1-374.e6.

4. Wright D, Spencer K, Kagan K, Tørring N, Petersen $\mathrm{OB}$, Christo A, Kallikas J, Nicolaides KH. First-trimester combined screening for trisomy 21 at 7-14 weeks' gestation. Ultrasound Obstet Gynecol 2010;36(4):40411.

5. Vera PG C, Letelier LM, Carvajal JA. Guía para el análisis crítico de estudios que evalúan exámenes diagnósticos. Rev Chil Obstet Ginecol 2005;70(3):196202. 